\title{
COMO AVANÇAR NO ESTUDO DO LÉXICO DE ORIGEM AFRICANA NA AMÉRICA LATINA?
}

\author{
Laura ÁLVAREZ LÓPEZ
}

Departamento de Espanhol, Português e Estudos Latino-americanos da Universidade de Estocolmo - ISPLA

\section{RESUMO}

O texto discute metodologias adequdas para o desenvolvimento de uma base de dados de léxico de origem africana em variedades de espanhol e de português na América Latina com o objetivo de abrir uma trilha para discutir e elaborar preliminares teórico-metodológicos a serem aplicados em pesquisas futuras. Mostra-se ainda a possibilidade de articulação de várias frentes de trabalho para as quais se tornará necessário realizar uma série de estudospiloto de caráter lexicográfico e metalexicográfico paralelamente ao desenvolvimento da base de dados. Espera-se poder testar um conjunto de hipóteses e elaborar abordagens teórico metodológicas que resultem adequadas para um estudo sistemático e abrangente do léxico de origem africana na América Latina a partir das fontes disponiveis.

\section{ABSTRACT}

The text discusses adequate methodologies for the development of a database including lexicon of African origin in varieties of Latin American Spanish and Portuguese. The aim is to start a discussion about the elaboration of theoretical and methodological approaches to be applied in future research. It also points out the possibility of articulation of various work fronts operating at the same time for which it will become necessary to perform lexicographical and metalexicographical pilot studies alongside the development of the database. The idea is to test a set of hypotheses and elaborate theoretical and methodological approaches that result suitable for a systematic and comprehensive study of the lexicon of African origin in Latin America using the available sources.

(C) Revista da ABRALIN, v.11, n.2, p. 203-225, jul./dez. 2012 


\section{PALAVRAS-CHAVE}

Africanismos. Contato linguístico. Léxico do Espanhol americano. Léxico do Português americano. Palavras e decalques de origem africana em espanhol e português.

\section{KEYWORDS}

African words and calques in Spanish and Portuguese, Language Contact. American Portuguese Lexicon, American Spanish Lexicon.

\section{Introdução}

Uma das diferenças observadas entre variedades europeias e americanas das línguas ibero-românicas é a presença, em solo americano, de vocábulos de origem africana que não estão presentes nas modalidades europeias das línguas em questão. No Brasil, os primeiros registros dessas palavras datam do século XVI (PETTER, 2002: 128). No primeiro dicionário monolíngue de português, elaborado por Moraes Silva (1789), aparecem os primeiros itens lexicais de origem africana, classificados como brasileirismos. Não obstante, Bonvini (2002) questiona a compreensão das palavras de origem africana no português brasileiro como brasileirismos, mostrando que alguns dos vocábulos assim classificados já tinham sido registrados em dicionários anteriormente publicados em Portugal.

$\mathrm{Na}$ segunda metade do século XIX foram publicadas as primeiras obras lexicográficas que destacam a peculiaridade do português no Brasil (BIDERMAN, 2002: 70-71) e as primeiras publicações que abordam a "influência Africana" no português brasileiro datam da primeira metade do século XX (ver LAYTANO, 1936; MENDONÇA, 1933; MACHADO FILHO, 1944; RAIMUNDO, 1933; RIBEIRO, 1939; SENNA, 1934, 1938). 
A partir da década de 1960 se realizam trabalhos baseados em dados coletados em comunidades afroreligiosas ou comunidades de afrodescendentes cujos membros utilizam itens lexicais de origem africana (ÁLVAREZ LÓPEZ, 2004; ANGENOT, JAQUEMIN; VINCKE, 1974, 1976; BYRD, 2005; CACCIATORE, 1977; CASTRO, 1976; CASTRO, 2001; PÓVOAS, 1989; QUEIROZ, 1998; VOGT; FRY, 1996). Várias publicações tomam como ponto de partida o léxico de origem africana apresentado em pesquisas anteriores (SCHNEIDER, 1991; BOLOUVI, 1994; LOPES,, 1993-1995). Atualmente, muitos dos termos de origem africana podem ser encontrados em dicionários brasileiros como o Houaiss e o Novo Aurélio do século XXI, apesar das inconsistências apontadas no que diz respeito ao léxico de origem africana nessas obras (PETTER, 2002: 137-140; 2003). Há ainda estudos recentes sobre léxico de origem africana no Brasil em várias coletâneas publicadas no século XXI (ÁLVAREZ LÓPEZ; COLL, 2012; BARTENS, BAKER, 2012; FIORIN; PET'TER 2008; PETTER; VANHOVE, 2011).

$\mathrm{Na}$ América hispânica existem compilações e inventários de palavras de origem africana produzidos de forma independente a partir da primeira metade do século XX na Argentina (ORTIZ ODERIGO, 2007), na Colômbia (CASTILLO MATHIEU, 1982, 1984; CAICEDO, 1994), em Cuba (ORTIZ, 1922, 1924; CABRERA, 1971; LÓPEZ MORALES, 1970; VALDÉS BERNAL, 1978), no Panamá (JAMIESON, 1992), no Peru (ROMERO, 1988), em Porto Rico (ÁLVAREZ NAZARIO, 1974; MEGENNEY, 1981), na República Dominicana (MEGENNEY, 1990), na Venezuela (ÁLVAREZ 1987; MEGENNEY 1999) e no Uruguai (ÁLVAREZ LÓPEZ, 2007, 2009; ÁLVAREZ LÓPEZ; COLL, 2012; COLL, 2010; LAGUARDA TRÁS, 1969; PEREDA VALDÉS, 1937, 1965).

Atualmente, a presença de vocábulos de origem africana nos dicionários não especializados nesse tipo de vocabulário parece ser 
mais limitada para o espanhol do que para o português brasileiro. No Diccionario de la Real Academia Española (DRAE, 2001) aparecem apenas 13 itens com a indicação de origem africana (BARTENS, 2012: 62), enquanto os dicionários brasileiros Houaiss e Aurélio, sem ser exaustivos, já apresentam um número maior, embora limitado, de "africanismos" (PETTER, 2003).

O problema é que, apesar da existência dos trabalhos acima mencionados, o estudo dos chamados "africanismos" nas variedades americanas do espanhol e do português é fragmentário e ainda não foi explorado o suficiente. Um outro problema é que os estudos que focalizam o léxico de origem africana são de caráter empírico e carecem de reflexões aprofundadas sobre as metodologias utilizadas na sua elaboração e de discussões de caráter teórico sobre o processo de integração desses vocábulos nas variedades em que são encontrados.

\section{Objetivos}

O objetivo deste trabalho é apresentar uma proposta que consiste no desenvolvimento de um banco de dados para o estudo de africanismos lexicais a partir da compilação de vocábulos recolhidos nas fontes lexicográficas latinoamericanas acima mencionadas. A escolha das fontes justifica-se pelo fato de se limitarem ao léxico de origem africana em diversas regiões da América Latina. A base de dados poderá servir como base para um dicionário online que, além de permitir um estudo sistemático do léxico de origem africana nas variedades em questão, vise a preservar informação sobre a herança linguística africana para gerações futuras (cf. SVENSÉN, 2009: 1).

Para começar, considera-se necessário realizar uma série de estudospiloto, cujos resultados poderão ser utilizados na elaboração de um contexto teórico-metodológico a ser aplicado no estudo do léxico de origem africana na América Latina. Por um lado, pretende-se discutir como sistematizar os dados de que se dispõe, criando uma base de dados 
que recolha toda a informação disponível sobre os vocábulos de origem africana presentes em uma série de fontes lexicográficas especializadas no vocabulário de origem africana registrado em diversas regiões e períodos. Por outro lado, procura-se desenvolver uma metodologia para descrever e analisar essas mesmas fontes de forma padronizada a fim de poder interpretar devidamente um amplo conjunto de dados.

\section{Justificativa}

Um estudo sistemático tem potencial para fornecer mais informações sobre o papel das línguas africanas na formação de variedades de português e espanhol americano. Nesse sentido, os dados históricos e demográficos apresentados em estudos realizados por historiadores durante a última década, podem ser aproveitados para limitar o número de línguas nas quais devemos procurar os étimos, ao mesmo tempo que a identifição dos étimos nos ajuda a completar a informação apresentada pelas fontes históricas, permitindo-nos gerar novos conhecimentos sobre a disseminação de falantes de diferentes línguas africanas na América Latina (ÁLVAREZ LÓPEZ, 2012).

Em uma publicação recente sobre o léxico de origem africana em línguas crioulas e línguas europeias transplantadas, Bartens afirma que

"A comprehensive study of African words retained in Latin American Spanish and Portuguese [...] constitutes both a desideratum and a major challenge which would best be taken up by an entire team of linguists familiar with both Romance and African languages" (2012: 51).

Concordamos com a mencionada autora sobre a necessidade do estudo e constatamos que a comparação de itens lexicais de origem africana em variedades de espanhol e português americano já se mostrou proveitosa para pesquisas anteriores que identificaram etimologias 
de palavras de origem africana em variedades de espanhol através da consulta de estudos sobre os mesmos itens lexicais realizados no Brasil (ÁLVAREZ, 2007, 2009; ÁLVAREZ; COLL, 2012).

O caráter inovador dos artigos incluídos na antologia editada por Bartens e Baker (2012) está na metodologia seguida pela maioria dos autores, que:

1) revêem as etimologias propostas em estudos anteriores por meio da consulta de dicionários de línguas africanas e propõem etimologias alternativas quando necessário;

2) analisam a distibuição das palavras em um conjunto de 12 domínios semânticos bem definidos;

3) estudam a correlação entre as línguas de origem da população africana a partir dos dados demográficos e a origem das palavras encontradas em termos estritamente locais.

Ao discutir a origem do léxico coletado em diferentes regiões da América Latina, Bartens (2012) explica que a maioria dessas palavras não são restritas a regiões ou grupos específicos e que muitas delas adotaram morfologia ibero-românica e já não são identificadas como estrangeirismos. É o caso, por exemplo, de samba, sambista, sambódromo.

Esses resultados poderão ser verificados ou não a partir do estudo de um conjunto mais amplo de itens lexicais que nos permitirá discutir os mecanismos que estão na base dos processos de mudança linguística. Winford (2003a: 17) aponta que os empréstimos lexicais podem levar a alterações fonéticas, fonológicas e morfológicas. Um exemplo disso é o uso de palavras francesas no inglês dos séculos XV e XVI, que teve como resultado a adoção de morfemas gramaticais como - able junto com morfemas lexicais de raiz inglesa (como em speakeable) pela população anglófona. Também é destacado o fato de ter surgido, nessa mesma população anglófona e através dos empréstimos lexicais do francês, uma distinção anterioremente inexistente entre alofones como [v] e [f] 
(WINFORD, 2003b:134-35). Dessa forma esperamos poder generalizar alguns dos resultados da pesquisa em relação aos processos de mudança linguística observados para outros contextos sociolinguísticos.

Cabe aqui salientar que o objetivo da proposta dos estudos- piloto de caráter lexicográfico e metalexicográfico é apenas abrir uma trilha para discutir e elaborar preliminares teórico-metodológicos a serem aplicados em pesquisas futuras. Ao definir um modelo para uma base de dados que reúna diferentes registros já existentes partindo de um conjunto de critérios comuns de inscrição na base, a presente proposta traz uma entrada dupla de análise, já que contempla tanto a etimologia como os processos de mudança linguística. A compreensão dos processos de mudança e a integração dos vocábulos de origem africana presentes nas variedades latino-americanas das línguas ibéricas podem ainda facilitar o trabalho de interpretação da etimologia dos mesmos, já que esta é difícil de traçar.

\section{Proposta para o estudo sistemático do léxico de origem africana na América Latina}

A presente proposta requer o desenvolvimento e a articulação de várias frentes de trabalho para as quais se propõe uma série de estudos-piloto de caráter lexicográfico e metalexicográfico.

\section{Abordagem lexicográfica - possibilidades e limitações}

A abordagem lexicográfica consiste no desenvolvimento de um banco de dados de africanismos lexicais a partir da compilação de vocábulos recolhidos nas fontes lexicográficas latinoamericanas acima mencionadas. A escolha dessas fontes justifica-se pelo fato de se limitarem ao léxico de origem africana em diversas regiões da América Latina. 
O primeiro passo consiste na escolha de um número limitado de vocábulos a serem inseridos em uma base de dados através do software LexiquePro (www.lexiquepro.com). Em uma primeira etapa, será incluída uma dezena de vocábulos registrados nas fontes secundárias acima mencionadas, isto é, fontes lexicográficas especializadas no vocabulário de origem africana em diversas regiões da América Latina.

O software irá facilitar a a comparação de formas sob as quais encontramos um mesmo vocábulo (cf. BONVINI 2002), classe de palavras à qual pertence (substantivo, adjetivo, advérbio, preposição, pronome, verbo, outros), significados que lhe são atribuidos (variam conforme regiões e períodos), fontes nas quais o termo foi registrado, regiões e períodos nos quais aparece, etimologias propostas (revisando etimologias indicadas e propondo etimologias alternativas quando necessário, cf. FARQUHARSON; BAKER, 2012: 156), classificação em campos semânticos (pessoas, flora, fauna, comidas/bebidas, lazer, trabalho, nomes de lugares, crenças/costumes, anatomia/ vestimentas, vida doméstica, coisas desagradáveis, sem classificação, cf. BAKER, 2012a: 88-92).

Conforme Burke (2003: 242-244) a macroestrutura do dicionário online deve possibilitar que o usuário faça buscas por palavras, classes de palavras, todos os derivados de um vocábulo, registro de uso, região de uso, campos semânticos e conteúdo fonológico. Quanto à microestrutura, o mesmo autor propõe que se evitem as abrevaituras e que se inclua informação de caráter flexional e exemplos de uso (BURKE, 2003: 246247).

Certamente não haverá informação disponível para todos os vocábulos que serão retirados de diversas fontes secundárias, mas existe a possibilidade de procurar exemplos auténticos de uso em corpora de espanhol e português (cf. SVENSÉN, 2009: 284). Para esse fim podese utilizar os corpora de espanhol disponibilizados pela Real Academia Española (Corpus diacrónico del español e Corpus del Español actual, www. rae.es) e os corpora de português de Davies e Ferreira (2006-, ver 
corpusdoportugues.org) e o Corpus brasileiro (que será disponibilizado em corpusbrasileiro.pucsp.br).

Seguindo a proposta de Bartens e Baker (2012), o trabalho inclui diversos passos:

\section{a) Revisão de etimologias propostas e propostas de etimologias alternativas quando necessário.}

Sabemos que não será possível encontrar a maioria das palavras que nos ocupam em dicionários etimológicos de português e espanhol (cf. SVENSÉN 2009: 334), mas sempre que possível procuraremos indicar o ano do primeiro registro de cada vocábulo. As etimologias propostas em estudos anteriores serão verificadas por meio da consulta de dicionários de línguas africanas relevantes, visando a eliminar possíveis erros e malentendidos e propor etimologias alternativas quando necessário (cf. FARQUHARSON; BAKER, 2012). Cabe aqui acrescentar que é importante representar o significado do étimo de maneira que a relação com o sentido atual fique clara e que consideramos igualmente relevante mencionar as etimologias populares (SVENSÉN, 2009: 337).

Um dos problemas apontados em estudos prévios é a dificuldade de identificação dos étimos, já que depende da disponibilidade de dicionários de línguas africanas (BARTENS; BAKER, 2012). São muitas as línguas que estiveram presentes na América Latina e a documentação linguística e demográfica de que se dispõe atualmente é escassa. As descrições das línguas africanas, quando existem, podem ser superficiais e os conhecimentos sobre a sua história são, com frequência, escassos. Além disso, salienta-se que a participação de falantes nativos das línguas em questão neste campo de estudos é limitada. 
No que diz respeito à origem dos vocábulos registrados na América Latina, Bartens (2012) observa, nos dados por ela analisdos, uma predominância das línguas do grupo Banto. $\mathrm{O}$ estudo de um conjunto de dados mais amplo poderá confirmar ou não essa tendência.

\section{b) Análise da distribuição das palavras nos domínios semânticos definidos e sua relação com fatores sócio- históricos em termos estritamente locais.}

Em alguns casos foi observado que os resultados mudam, por exemplo, quando o léxico relativo ao campo das crenças e costumes é excluído (BAKER, 2012b: 124-125), mas em geral os resultados de estudos anteriores indicam que a distribuição em diversos campos semânticos varia e que o vocabulário afro não se restringe unicamente a campos relacionados com a vida dos escravos. Os resultados obtidos poderão ser comparados com os apresentados na coletânea de Bartens e Baker (2012).

\section{c) $O$ estudo da correlação entre línguas de origem das palavras encontradas e os dados demográficos de que dispomos.}

Uma das hipóteses apresentadas por Philip Baker (2012c: 283) é que os grupos que tiveram maior peso demográfico no periodo inicial contribuíram com mais palavras e com mais itens que não pertencem à classe dos substantivos. Considera-se aqui importante explorar essa hipótese pelo aproveitamento de fontes secundárias com informação demográfica (censos, inventários, etc, cf. ÁLVAREZ LÓPEZ, 2012). 


\section{d) Discussão sobre o significado da proporção de palavras de diferentes classes provenientes de diferentes línguas.}

Já foi constatado que o empréstimo de adjetivos, verbos e advérbios ocorre com menos frequência que o empréstimos de substantivos (BARTENS; BAKER, 2012). Por isso, a concentração de verbos ou adjetivos de uma certa língua africana em uma variedade ibero-românica pode indicar que a língua africana de origem teve um papel mais importante ou especializado do que outras na formação da variedade em questão (cf. LADHAMS, 2012). É importante explorar essa hipótese em termos estritamente locais para as variedades analisadas.

No que diz respeito à presença de um mesmo vocábulo em mais de uma variedade de espanhol ou português há, conforme Bartens (2012) três explicações possíveis, ou hipóteses, que poderão ser testadas:
1) origem comum e difusão;
2) origem comum e adoção paralela;
3) processos de reafricanização.

Cabe aqui notar que as palavras introduzidas através dos processos de reafricanização observados nas últimas décadas, devem ser estudadas separadamente (cf. ÁLVAREZ LÓPEZ, 2004; BARTENS, 2012).

\section{Abordagem metalexicográfica - possibilidades e limitações \\ O foco dos estudos-piloto propostos nesta seção está na formação discursiva e visa investigar o que os dicionários ou glossários fazem com as palavras apresentadas. Interessa-nos o modo como os dicionários, ao descrever as palavras de origem africana, produzem discursos sobre a África, os africanos e as suas línguas. Vários estudos anteriores discutem}


questões teóricas e metodológicas reltivas a esse tipo de abordagem e articulam pressupostos da lexicografia, da análise do discurso e do campo de pesquisa relativo à história das ideias linguísticas (ver, por exemplo, ELIA, 2006; HORTA, 1996; REY, 1977).

A abordagem propõe o estudo crítico das fontes lexicográficas utilizadas. Conforme Horta (2002), tais fontes constituem instrumentos linguísticos e objetos discursivos, que podem ser analisados por meio da articulação da análise do discurso com a história das ideias linguísticas. Entende-se aqui que os dicionários são o resultado de um certo contexto que ao mesmo tempo constroem. Parte-se ainda do pressuposto de que os dicionários são discursos sociais muito importantes cuja autoridade é pouco questionada na vida pública (HORNSCHEIDT, 2008). São ferramentas utilizadas com frequência pelas pessoas que neles procuram informações, e constituem materiais adequados a partir dos quais poderá ser realizada uma análise crítica do discurso.

A metalexicografia estuda, entre outas coisas, o sentido das explicações, analisando as normas e os valores que os dicionários refletem. Pode-se, por isso, estudar a produção e negociação do racismo no contexto colonial ou pós-colonial através de obras lexicográficas, por exemplo, analisando os mecanismos de construção, reprodução e naturalização de atitudes racistas a nível discursivo (HORNSCHEIDT, 2008). Uma abordagem possível no campo da linguística afro-latina é o estudo da manifestação do preconceito através da análise da escolha das palavras utilizadas na definição das unidades lexicais, dos exemplos e das acepções atribuídas aos vocábulos (cf. CORREIA, 2006).

A ideia é discutir, por exemplo, o fato de vários etnônimos africanos adquirirem conotações negativas (cf. ÁLVAREZ LÓPEZ, 2012). Pretende-se elaborar estratégias para localizar fatores ideológicos e pensar nas suas consequências, refletir sobre a possibilidade de definir se os preconceitos estão no léxico/na sociedade ou no lexicógrafo e tentar identificar de quem é a perspectiva que aparece nos dicionários e 
glossários utilizados. A análise deve destacar a maneira como os discursos expressam ideologias e reproduzem preconceitos ou inequidades (de gênero, raça e classe) e relações de poder, e analisar a construção da imagem do "nós" e do "outro". Para esse fim, torna-se necessário discutir de que forma o discurso reproduz a dominação social, o abuso de poder de um grupo em suas relações com outro grupo e ter em conta como os grupos dominados resistem a isso na sociedade atual (como, no caso atualmente em debate no Uruguai, no qual organizações de afrodescendentes propõem seja alterado o significado da palavra ‘quilombo' que no espanhol do Prata significa 'prostíbulo' ou 'bagunça', voltando seu significado "original”, que na verdade talvez não seja o significado "original" em espanhol).

Pretende-se ainda comparar os discursos presentes nas fontes que se limitam à recopilação de palavras identificadas como africanismos com os dicionários atuais não especializados. Foram escolhidas para esse fim, assim como em trabalhos anteriores, as versões online do Diccionario de la Real Academia española para a língua espanhola e dos dicionários Houaiss e Aurélio para a língua portuguesa (cf. ÁLVAREZ LÓPEZ, 2012).

\section{Propõem-se três estudos pilotos para esta abordagem:}

- O primeiro estudo analisa e compara os trabalhos lexicográficos que apresentam ideias intressantes, ou construções discursivas, sobre conceitos como africanismo, afrobrasileirismo ou influência afro-rio-platense e que remetem, com frequência, às mesmas fontes. Pretende-se elaborar uma metodologia para apresentar essas fontes lexicográficas minuciosamente, descrevendo o tipo de fonte, analisando os prefácios e introduções, discutindo os critérios de seleção das palavras de cada texto (se os vocábulos provêm de fontes escritas ou da língua falada; se há informações sobre os grupos sociais ou étnicos que supostamente utilizam as palavras), descrever a macroestrutura (conjunto de entradas) 
e a microestrutura (marcação grammatical, definição, exemplos, etimologia) da obra. Interessa-nos dicutir como se constrói o discurso no que diz respeito à imagem das línguas africanas, da presença africana, do que é um africanismo, etc.

- O segundo estudo analisa o verbete quilombo e seus derivados em variedades de espanhol e português a partir dos significados outorgados à palavra e exemplos concretos de uso inventados ou citados. Nesse sentido, torna-se interessante analisar os comentários metalinguísticos (como os dicionários e glossários naturalizam certos usos e avaliam outros?) e a informação etimológica formecida. Pretende-se ainda discutir como identificar fatores ideológicos nos textos, questionar os significados geralmente atribuídos aos vocábulos e fazer uma reconstrução do seu uso com documentos históricos.

- O terceiro trabalho toma como objeto de estudo algumas unidades lexicais que denotam preconceitos existentes na sociedade (alguns nomes de nação já discutidos em estudos anteriores, como cassange e benguela, cf. ÁLVAREZ LÓPEZ, 2012). A ideia é observar as acepções pejorativas que revelam características estereotípicamente atribuidas ao grupo: "Ao nome está associado um número expressivamente vasto de nomes coletivos com conotações pejorativas" (CORREIA, 2006: 157). Pretende-se assim analisar a construção discursiva dos verbetes para avaliar traduções e transições dos sentidos. Como é que o etnônimo, ou nome de nação, se transforma em adjetivo pejorativo? 


\section{Resultados esperados}

Ao criar uma base de dados e realizaros estudos pilotos acima descritos será possível testar uma série de hipóteses e elaborar abordagens teórico metodológicas que resultem adequadas para um estudo sistemático e abrangente do léxico de origem africana na América Latina a partir das fontes disponíveis.

O desenvolvimento da base de dados e da metodologia acima discutida serve não só para a inscrição dos vacábulos na base, mas para desenvolver análises matelexicográficas e de funcionamento lexical em diferentes textualidades. No caso do estudo que será realizado a partir de documentação histórica sobre uma palavra específica, este visa a gerar discussões aprofundadas para melhor compreensão dos dados, das fontes e dos processos de integração de tais vocábulos nas variedades estudadas.

O resultado esperado é que os estudos pilotos possam servir de base para a elaboração de projetos futuros, que deverão incluir uma equipe de pesquisadores e ser planejados a longo prazo.

\section{Referências}

ÁLVAREZ, Alexandra. Malabí Maticulambí: estudios afrocaribeños. Montevideo: Monte Sexto, 1987.

\footnotetext{
ÁLVAREZ LÓPEZ, Laura. A língua de Camões com Iemanjá. Forma e funções da linguagem do candomblé. Tese de doutorado. Estocolmo: Universidade de Estocolmo, ISPLA, 2004.

. Un breve ejemplo del mundo afrolatino: ¿así hablaban los afrouruguayos?. Moderna Språk 101:1, 2007. p.73-89.

'Canto patriótico de los negros': registro de una práctica lingüística afrouruguaya. Revista de la Academia Nacional de Letras 4: 6-7, 2009. p. 137-166.
} 
. Lubolos, mandingas y otros "nombres de nación" de origen africano en Montevideo y Rio Grande do Sul”. In: ÁLVAREZ LÓPEZ, Laura; COLL, Magdalena. (eds.) Una historia sin fronteras: léxico de origen africano en uruguay y Brasil. Estocolmo: Acta Universitatis Stockholmiensis, 2012. p. 35-70.

ÁLVAREZ LÓPEZ, Laura; COLL, Magdalena (eds.) Una historia sin fronteras: léxico de origen africano en uruguay y Brasil. Estocolmo: Acta Universitatis Stockholmiensis. 2012.

ÁLVAREZ NAZARIO, Manuel. El elemento afronegroide en el español de Puerto Rico. San Juan de Puerto Rico: Instituto de Cultura Puertorriqueña. 1974.

ANGENOT, Jean-Pierre; JACQUEMIN, Jean-Pierre; VINCKE, Jacques. Répertoire des vocables brésiliens d'origine africanine. Collection "Travaux et Recherches", Cellule V. Lubumbashi: Université Nationale du Zaïre. 1974.

- Identificação de critérios linguísticos que permitem precisar a origem dos empréstimos bantos no português do Brasil, comunicação apresentada na X Reunião Brasileira de Antropologia, Salvador, Bahia, 22-25 de fev. 1976.

BAKER, Philip. African words and calques in Mauritian Creole. In: BARTENS, Angela; BAKER, Philip (eds.) (2012) Black through white. African words and calques which survived slavery in Creoles and transplanted European languages. London: Battlebridge, 2012a. p. 81116.

. The African vocabulary of Haitian and the Lesser Antilles French Creoles. In: BARTENS, Angela; BAKER, Philip (eds.) (2012) Black through white. African words and calques which survived slavery in Creoles and transplanted European languages. London: Battlebridge, 2012b. p. 117-133. 
. Interpreting the findings. In: BARTENS, Angela; BAKER, Philip (eds.) (2012) Black through white. African words and calques which survived slavery in Creoles and transplanted European languages. London: Battlebridge, 2012c. p. 273-286.

BARTENS, Angela. Lexical Africanisms in Latin American Spanish and Portuguese. In: BARTENS, Angela; BAKER, Philip (eds.) (2012) Black through white. African words and calques which survived slavery in Creoles and transplanted European languages. London: Battlebridge, 2012. p. 51-72.

BARTENS, Angela; BAKER, Philip. (eds.) Black through white. African words and calques which survived slavery in Creoles and transplanted European languages. London: Battlebridge. 2012.

BIDERMAN, Maria Tereza Camargo. A formação e a consolidação da norma lexical e lexicográfica no português do Brasil. In: HORTA NUNES, José; PETTER, Margarida (Org.) História do saber lexical e constituição de um léxico brasileiro. São Paulo: Humanitas/FFLCH/ USP: Pontes, 2002. p. 65-82.

BOLOUVI, Lébéné P. Nouveau dictionnaire etymologique afrobrésilien. Lomé: Presses de l’Université du Bénin. 1994.

BURKE, Sean M. The design of online lexicons. In: STERKENBURG, Pietvan (ed.) A Practical Guide to Lexicography. Amsterdam/ Philadelphia: John Benjamins, 2003. p. 240-249.

BYRD, Steven. Calunga, an Afro-Brazilian speech of the Triângulo Mineiro: Its grammar and history. Tese de doutorado, Austin: University of Texas. 2005. 
CABRERA, Lydia. [1954] El monte, igbo finda, ewe orisha, vititi nfinda (notas sobre las religions, la magia, las supersticiones y el folclore de los negros criollos y del pueblo de Cuba). Miami: Colección de Chicherekú. 1971.

CACCIATORE, Olga. Dicionário de cultos afro-brasileiros. Rio de Janeiro: Forense. 1977.

CAICEDO, Miguel A. E1 Castellano en el chocó (500 años). Medellín: Quibdó. 1994.

CASTILLO Mathieu, Nicolás del. Esclavos negros en Cartagena y sus aportes léxicos. Bogotá: Instituto Caro y Cuervo. 1984.

El léxico negro-africano de San Basilio de Palenque. Bogotá: Instituto Caro y Cuervo. 1984.

CASTRO, Yeda Pessoa de. De l'integration des apports africains dans les parlers de Bahia au Brésil. Tese de doutorado, Universidade Nacional do Zaire. 1976.

. Falares Africanos na Bahia. Um Vocabulário Afro-Brasileiro. Rio de Janeiro: Topbooks. 2001.

COLL, Magdalena. E1 habla de los esclavos africanos y sus descendientes en Montevideo en los siglos XVIII y XIX: representación y realidad. Montevideo: Academia Nacional de Letras. 2010.

CORREIA, Margarida. A discriminação racial nos dicionários de língua: tópicos para discussão, a partir de dicionários portugueses contemporâneos. Revista Alfa 50:2 2006. p. 155-171.

ELIAS, Sheila de Oliveira. Cidadania. História e política de uma palavra. Campinas: Pontes editora. 2006. 
FARQUHARSON, Joseph; BAKER, Philip. African morphemes in Jamaican Creole. In: BARTENS, Angela; BAKER, Philip. (eds.) (2012) Black through white. African words and calques which survived slavery in Creoles and transplanted European languages. London: Battlebridge 2012. p. 155-168.

FIORIN, José Luiz; PETTER, Margarida. (Org.) África no Brasil: a formação da língua portuguesa. São Paulo: Contexto. 2008.

Grande Dicionário Houaiss da Língua Portuguesa [online]. $<$ http://houaiss.uol.com.br>

HORNSCHEIDT, Antje. A concrete research agenda for critical lexicographic research within critical discourse studies: an investigation into racism/colonialism in monolingual Danish, German, and Swedish dictionaries. Critical Discourse Studies 5:2 2008. p. 107132.

HORTA NUNES, José. Discurso e instrumentos linguísticos no Brasil: dos relatos de viajantes aos primeiros dicionários. Tese de doutorado, IEL, UNICAMP. 1996.

. Dicionarização no Brasil: condições e processos. In: HORTA NUNES, José; PETTER, Margarida (Org.) História do saber lexical e constituição de um léxico brasileiro. São Paulo: Humanitas/FFLCH/ USP: Pontes, 2002. p. 99-120.

JAMIESON, Martín. Africanismos en el español de Panamá. Anuario de Lingüística Hispánica 8: 1992. p. 149-166.

LADHAMS, John. Article agglutination and the African contribution to the Portuguese-based Creoles. In: BARTENS, Angela; BAKER, Philip (eds.) (2012) Black through white. African words and calques which survived slavery in Creoles and transplanted European languages. London: Battlebridge, 2012. p. 31-50. 
LAGUARDA TRÍAS, Rolando. Afronegrismos rioplatenses. Separata del Boletín de la Real Academia Española. Tomo XLIX, Cuaderno CLXXXVI, 1969. p. 27-116.

LAY'TANO, Dante de. Os africanismos do dialeto gaúcho. In: Separata da Revista do Instituto Histórico e Geográfico do Rio Grande do Sul. II Trimestre do ano XVI. 1936.

LOPES, Nei. Novo Dicionário Banto do Brasil. Pallas: Rio de Janeiro. 2006.

MACHADO FILHO, Aires da Mata. [1943] O negro e o garimpo em Minas Gerais. 2ª ed. Rio de Janeiro: José Olympio. 1944.

LÓPEZ MORALES, Humberto. Estudio sobre el español de Cuba. New York: Las Américas. 1970.

MEGENNEY, William. Sub-Saharan influences in the lexicon of Puerto Rico. Orbis 30, 1981. p. 214-260.

Africa en Santo Domingo: su herencia lingüística. Santo Domingo: Editorial Tiempo. 1990.

Aspectos del lenguaje afronegroide en Venezuela. Iberoamericana: Madrid/ Vervuert Verlag: Frankfurt am Main. 1999.

MENDONÇA, R. [1933] A influência africana no português do Brasil. 4a ed. Rio de Janeiro: Civilização Brasileira. 1973.

MORAES SILVA, Antonio. Diccionario da lingua portugueza - recompilado dos vocabularios impressos ate agora, e nesta segunda edição novamente emendado e muito acrescentado, por MORAES SILVA, Antonio de. Lisboa: Typographia Lacerdina. 1789. 
ORTIZ ODERIGO, Néstor. Diccionario de africanismos en el castellano del Río de la Plata. Caseros: Editorial de la Universidad Nacional de Tres de Febrero. 2007.

ORTIZ, Fernando. Los afronegrismos en nuestro lenguaje. Revista Bimestre 17: 1922. p. 321-336.

Glosario de afronegrismos. Habana: El Siglo XX. 1924.

PEREDA VALDÉS, Ildefonso. E1 negro rioplatense y otros ensayos. Montevideo: Claudio García e cía. 1937.

. El negro en el Uruguay. Pasado y Presente. Revista del Instituto Histórico y Geográfico del Uruguay XXV. 1965.

PETTER, Margarida. Termos de origem africana no léxico do português do Brasil. In: HORTA NUNES, José; PETTER, Margarida (Org.) História do saber lexical e constituição de um léxico brasileiro. São Paulo: Humanitas/FFLCH/USP: Pontes, 2002. p. 123-145.

. Palavras de origem africana nos dicionários Houaiss e Novo Aurélio século XXI. Papia 13: 2003. p. 107-114.

PETTER, Margarida; VANHOVE, Martine. Portugais et langues africaines. Études afro-brésiliennes. Paris: Karthala. 2011.

PÓVOAS, Rui do Carmo. A linguagem do candomblé. Níveis sociolinguísticos de integração afro-portuguesa. Rio de Janeiro: José Olympio. 1989.

QUEIROZ, Sônia. Pé preto no barro branco. A língua dos negros da Tabatinga. Belo Horizonte: Editora da UFMG. 1998.

RAIMUNDO, J. O elemento afro-negro na língua portuguesa. Rio de Janeiro: Renascença. 1933. 
REAL ACADEMIA ESPAÑOLA. Diccionario de lengua española [online]. 2001. 22ª ed. Madrid: Real Academia Española. Disponível em: <http://www.rae.es>

. (NTLL) [online]. Nuevo tesoro lexicográfico de la lengua española. Disponível em: <http:/ /www.rae.es> . Banco de datos (CORDE) [online]. Corpus diacrónico del español. Disponível em: <http://www.rae.es> . Banco de datos (CREA) [online]. Corpus de referencia del español actual. Disponível em: <http://www.rae.es>

REY, Alain. Le lexique: images et modèles. Du dictionnaire á la lexicologie. Paris: Armand Colin. 1977.

RIBEIRO, João. O elemento negro. História - Folklore - Linguística. Rio de Janeiro: Record. 1939.

ROMERO, Fernando. Quimba fa, malabo, ñeque. Afronegrismos en el Perú. Lima: Instituto de estudios peruanos. 1988.

SCHNEIDER, John. Dictionary of African borrowings in Brazilian Portuguese. Hamburg: H. Buske. 1991.

SENNA, Nelson de. Africanismos na linguagem brasiliera. Revista de Philologia e de História 2, 1934. p. 439-449.

- Africanos no Brasil. Estudos sobre os Negros Africanos e Influências sobre a Linguagem e Costumes do Povo Brasileiro. Belo Horizonte: Queiroz Breyner. 1938.

SVENSÉN, Bo. A Handbook of Lexicography. The Theory and Practice of Dictionary-Making. Cambridge: Cambridge University Press. 2009. 
VALDÉS BERNAL, Sergio. Las lenguas africanas y el español coloquial de Cuba. Santiago, Revista de la Universidad de Oriente 31: 1978. p. 81-107.

VOGT, Carlos; FRY, Peter. Cafundó: A África no Brasil. Campinas: Editora da UNICAMP. 1996.

WINFORD, Donald. An Introduction to Contact Linguistics. Oxford: Blackwell. 2003a. "Contact-induced changes - classification and processes". OSUWPL 57(129-50). 2003b. Disponível em: <http://www.ling.ohiostate.edu/publications/osu_wpl/osuwpl_57/Don-WPL.pdf $>$ Acesso em: 02 jan. 2006. 